\title{
Ordem, empreendorismo e formalização: as novas funções para a pobreza urbana no Rio de Janeiro Global.
}

Mario Brum

Em 2008, no dia da eleição para prefeito do Rio de Janeiro, o jornal O Globo, o principal da cidade, estampava em sua primeira página uma foto do morro Dois Irmãos, ao fundo das praias de Ipanema e Leblon, áreas nobres e turísticas da cidade, destacando a favela do Vidigal com a seguinte questão: "Quem vai dar um jeito nisso?"_ seguido da legenda: "Favelização, trânsito caótico, desordem urbana e conservação de ruas são desafios para novo prefeito".

A manchete do Globo tratou-se da tentativa (a nosso ver, bem sucedida) por parte do maior grupo de comunicação do Brasil_s sediado no Rio de Janeiro e com ramificações em diversas atividades econômicas_de pautar a gestão do prefeito num período em que a economia do país estava em expansão, com taxas de crescimento acima de 4,0; 6,0 e 5,1 no triênio 2006 a $2008 .^{1}$

Nesse cenário, a cidade do Rio de Janeiro, dada suas relevância e projeção nacional e internacional, ocupava posição estratégica para setores empresariais e políticos. A leitura do Rio de Janeiro como território de vasta ilegalidade e informalidade pouco ou nada combatidas em gestões anteriores, ou até mesmo incentivadas, e que seriam responsáveis por travarem o desenvolvimento da cidade pelo clima de insegurança e desordem urbanas.

\footnotetext{
1 Ver "Indicadores Econômicos Consolidados" no site eletrônico do Banco Central do Brasil (http://www.bcb.gov.br/?INDECO) Consultada em 10/02/2016
} 
Mais do que a linha editorial do jornal, o Globo expressava uma demanda anteriormente articulada de setores empresariais, como a Associação Comercial do Rio de Janeiro (ACRJ), a Federação das Indústrias do Estado do Rio de Janeiro (FIRJAN), Sindicato das Indústrias de Construção Civil (Sinduscon), entre outros segmentos de maior poder aquisitivo. A partir da gestão de Eduardo Paes na prefeitura do Rio, articula-se uma nova configuração do Rio de Janeiro como cidade de projeção global, adotando como estratégia para lidar com os territórios de pobreza, notadamente as favelas, o incentivo ao empreendorismo e à formalização (serviços, comércio, fundiária), de forma que as favelas sejam incorporadas à ordem urbana para criação de um ambiente de negócios seguro. De um lado, reprimindo-se o que é ilegal, do outro, incentivando-se a aceitação de uma ordem através da incorporação subordinada ao estabelecido.

Desse modo, esse artigo visa ser uma breve contribuição com o debate sobre o atual momento da cidade do Rio de janeiro, distanciando-se da polarização entre o otimismo que rejeita qualquer crítica (recentemente com uso de forte repressão); e a crítica infantil que rejeita as mudanças em sua totalidade.

Para isso iremos relativizar ou confrontar diretamente algumas ideias que têm prevalecido nos anos recentes como dogmas de algumas pesquisas acadêmicas e dos movimentos sociais que tratam da questão urbana na metrópole do Rio de Janeiro. Mesmo quando há a compreensão de que processos mais profundos estão em curso, tende-se à simplificação desses com explicações esquemáticas que se resumem às dinâmicas do sistema capitalista.

Nossa análise parte do princípio que os Grandes Eventos são parte de um processo mais longo, mais articulado e mais profundo de reconfiguração de funções que se projetam para o Rio de Janeiro e, a partir disso, de mais um ciclo de reformas 
urbanas, em que surgem ou se incrementam áreas de expansão urbana, alteram-se os modais de transporte, áreas da cidade ganham novas funções e, dentro disso, implementam-se novas formas de gestão da pobreza urbana e/ou das favelas. ${ }^{2}$

Conjugam-se vários processos locais e nacionais, fortemente articulados, que explicam as intensas transformações que ocorrem nas favelas cariocas e no trato da pobreza urbana na segunda década do século XXI no Rio de Janeiro: o recente período de crescimento econômico, o aumento de renda das camadas mais baixas, o apoio ao consumo e ao empreendedorismo, reformas urbanas, expansão imobiliária, grandes investimentos em obras na cidade, sediar grandes eventos, pacificação de favelas, criação de um ambiente seguros de negócios, entre outros.

Tais processos têm atores (Estado, empresários, partidos, grandes grupos de mídia...) que direcionam suas ações e se unem, embora com interesses até conflitantes por vezes, num projeto de cidade. O que explica a sintonia entre as diferentes esferas administrativas, ainda que anteriormente pessoas ou partidos à frente dessas esferas tenham tido fortes embates ${ }^{3}$.

E aqui é nossa hipótese principal: o sentido das políticas e ações na cidade e nas favelas cariocas, por esses atores, que hoje ocorrem no Rio de Janeiro é o processo de

\footnotetext{
${ }^{2}$ Vale considerar que a associação automática entre favela e pobreza urbana deva ser repensada pelo aumento da renda e do IDH da maior parte das favelas nos últimos anos ("Com IDH médio ou alto, comunidades da cidade deixam de ser redutos de miséria" O Globo, 12/07/2015) e também pelo fato de que a pobreza urbana é encontrada em outros territórios da cidade além das favelas.

${ }^{3}$ Eduardo Paes, quando deputado federal (2003-2007) foi um dos mais notórios críticos ao governo do Partido dos Trabalhadores no primeiro mandato presidencial de Lula (2003-2007), inclusive foi eleito inclusive pelo que se tornaria o principal partido de oposição ao PT, o Partido da Social Democracia Brasileira (PSDB). Após obter apenas $5,33 \%$ dos votos para governador do Estado do Rio em 2006, Paes deixou o PSDB, se filiou ao Partido do Movimento Democrático Brasileiro (PMDB), legenda do então novo governador Sergio Cabral Filho (também exPSDB) conseguindo apoio desse e de Lula na eleição para prefeito da cidade do Rio de Janeiro em 2008, indo para o segundo turno com $31 \%$ dos votos válidos (contra $25 \%$ do segundo colocado), e acabando por ser eleito com margem apertada de quase 51\% dos votos válidos. Ver http://g1.globo.com/Eleicoes2008/0,,MUL832458-15693,00EDUARDO+PAES+E+ELEITO+PREFEITO+DO+RIO+DE+JANEIRO.html (consultado em 07/05/2015).
} 
incorporação destas a uma ordem em que já há vencedores com ênfase na formalização e na 'abertura' destas a grandes agentes de mercado.

Nesse sentido, afirmamos que as UPPs e as remoções, embora sejam os elementos mais visíveis e dramáticos a curto prazo, não são as principais políticas direcionadas às favelas do Rio de Janeiro.

Mais uma vez a reconfiguração da cidade do Rio de Janeiro na busca de uma 'vocação' tem como um dos principais eixos como lidar com os pobres e os territórios da pobreza na cidade. Quando capital da República na virada do século XIX, tornar o Rio uma "Paris Tropical" implicava em eliminar os cortiços da paisagem urbana4; quando deixou de ser capital e passou a buscar uma vocação industrial os favelados foram removidos para conjuntos habitacionais a fim de servirem como mão-de-obra na planejada zona Industrial nas zonas norte e oeste da cidade (Brum, 2012).

Na quadra atual, a incorporação das favelas à ordem urbana, sob o signo do combate à ilegalidade e o incentivo à formalização rompe com as dinâmicas históricas de um estatuto indefinido das favelas _ não reconhecidas, mas também não ignoradas_ cedendo espaço, como nunca antes, às alterações no estatuto jurídico do solo e da moradia, à regularização do comércio local, à obras de mobilidade nas favelas que tratam de torná-las integradas aos bairros que as circundam, ao seu desadensamento, à abertura das favelas a grandes agentes de mercado, ao controle do seu espaço de diversas maneiras.

4 Para esse período ver Jaime Benchimol. Pereira Passos: um Haussman tropical. Disponível em http://www.rio.rj.gov.br/dlstatic/10112/4204210/4101387/pereira_passos_haussmann_carioca.pdf 


\section{A perda da Capital e a Guanabara: vocação industrial e o favelado como proprietário}

As atuais mudanças no Rio de Janeiro repetem outras ocasiões em que a conjuntura nacional se relaciona com os destinos da cidade, mas que possui lógica própria (o que não quer dizer que sua escala de atuação seja exclusivamente local) e dinâmicas internas da própria cidade, das lutas pelos seus espaços e de seus rumos.

Vimos isso no início da República, quando a consolidação do capitalismo implicou em um conjunto de reformas urbanas para modernizar a cidade (porto, avenidas, expulsão dos pobres das áreas centrais) (Vaz, 1985). A transformação do Rio numa moderna cidade capitalista refletiu-se e foi objeto de empenho do capital imobiliário em abrir novas áreas de expansão urbana, em que pesados investimentos públicos destinaram-se mais às áreas por se fazer através do capital, o que viria ser a nova Zona Sul (Copacabana, Ipanema e Leblon) do que áreas já construídas na cidade (os antigos subúrbios).

Recentes estudos, como o de Gonçalves (2013) têm desmentido a ideia da favela como "problema para o Estado X solução para os moradores". O que houve foi um jogo de interesses em que as favelas figuraram como solução também para o Estado e as elites, que de outro modo teriam de lidar com o problema de garantir habitação para grande parcela da mão de obra da cidade e os inerentes custos de reprodução da força de trabalho, no que teríamos uma cidade bem diferente da que veio a existir. Assim, a favela também foi solução ao Estado.

Outro momento chave foi em 1965, que ao completar seu IV Centenário, o Rio de Janeiro viveu um momento de redefinição. A cidade havia perdido a condição de capital federal em 1960, vendo ser levados ministérios, funcionários, recursos públicos etc, para a recém-inaugurada Brasília. 
A cidade tornara-se então o novo Estado da Guanabara, em busca de uma nova vocação. Soma-se a isso que seu primeiro governador, Carlos Lacerda era o principal político de oposição à aliança PTB/PSD, no poder desde o fim do Estado Novo, em 1945. Mantendo a cidade-estado, e particularmente sua administração em evidência, Lacerda se capitalizaria politicamente. Afinal, ainda que o Rio não fosse mais a capital da República, a cidade mantinha grande importância.

Como as eleições para presidência da República se dariam no ano do IV Centenário, Lacerda tinha cinco anos para fazer de sua administração uma plataforma. A cidade superaria a perda do status de capital através de um conjunto de obras e ações que a reconfigurariam e ordenariam seu espaço urbano, dotando o Rio de Janeiro da infraestrutura necessária para permitir a sua viabilidade econômica a partir de suas várias potencialidades. Resolvida a infra-estrutura, a economia carioca se desenvolveria através da realização da sua vocação industrial, com a realização efetiva do zoneamento já estabelecido desde o Código de Obras (Decreto nº.000), em 1937.

Se Lacerda começou seu governo fazendo obras pontuais em algumas favelas, a partir de 1962 ele dá uma guinada após receber recursos da USAID através do programa Aliança para o Progresso, reformulando seu governo e sua política para as favelas, que passou a se pautar pela remoção (Benmerguí, 2009).

Opção que seria aprofundada na Guanabara no final da década de 1960, já sob o governo Negrão de Lima em fina sintonia com o governo federal instaurado com o golpe Militar de 1964. De 1969 a 1973, exatamente os anos da maior expansão econômica promovida pela Ditadura, aproximadamente 175 mil pessoas foram removidas das favelas para os conjuntos habitacionais.

A tolerância que marcou a relação com as favelas até então_ com os favelados servindo de mão de obra para serviços sazonais e/ou de baixa qualificação, como peões 
de obra (trabalhador precário da construção civil), empregadas, babás, etc em meio aos bairros de classes média e alta _chegara ao fim, com a demanda em um mercado aquecido pelos valorizados terrenos da Zona Sul, até então ocupados por favelas, sendo liberados para empreendimentos imobiliários para classe média.

O que é demonstrado de forma inequívoca o editorial do Jornal do Brasil quando ocorre a remoção da Praia do Pinto, umas das maiores e mais antigas favelas da cidade que era situada bem no coração do Leblon, que no mercado imobiliário atual tem o metro quadrado mais caro do Brasil (mais de USD 7.000 pela tabela FIPE/ZAP em maio de 2015):

Transferindo essa gente para áreas urbanizadas, dando-lhes uma verdadeira casa, de modo a permitir que a criança favelada tenha, de fato, um conceito de lar, o Governo não beneficia apenas os moradores das favelas, mas, numa dimensão mais ampla, a própria cidade, que passa a dispor de áreas úteis para a construção de residências capazes de merecer o habite-se da Saúde Pública. ("Espírito comunitário" Jornal do Brasil, 11/03/1969)

Assim, além da busca da vocação industrial, a ser efetivada nas zonas norte e oeste da cidade, a Zona Sul, como veremos, se consolidaria como área turística e de moradia para as classes mais abastadas, no que as remoções de favelas e a transferência de seus moradores para conjuntos habitacionais cumpririam o papel de 'sanear' a zona Sul e dotar as áreas industriais com a mão de obra necessária.

Um estudo do Governo da Guanabara apresentava como um problema para as indústrias os longos e precários deslocamentos da mão-de-obra para os empregos nas 
fábricas, somada à falta da oferta de moradia acessível próxima a elas, de modo que isso era uma das explicações para o surgimento das favelas: "As dificuldades de residência nas proximidades destas fábricas compeliram a população operária a habitarem nas favelas situadas nas redondezas. No caso, sacrifica-se o conforto caseiro em benefício de uma menor dependência dos meios de condução." (Governo da Guanabara, 1969: 23)

Também para o IDEG (Instituto de Desenvolvimento da Guanabara), as zonas Norte e Sul da cidade possuem vocações distintas: “As regiões próximas ao Estado do Rio de Janeiro [a Zona Norte, principalmente a região limítrofe à Baixada Fluminense] passaram a adquirir uma conformação típica de zonas industriais, e as áreas que formam a zona sul da cidade começaram a se firmar, cada vez mais, como residenciais."(IDEG, 1969: 14)

Se Lacerda era ferrenho opositor da aliança PTB/PSD no governo federal, e crítico de suas políticas, cabe dizer que partilhou e implementou na Guanabara dois pilares do governo federal que ele tanto criticava: a industrialização como principal meio de desenvolvimento econômico, bem ao modelo cepalino em voga, e o rodoviarismo ${ }^{5}$. Ambos se conjugaram para, a partir da opção pela vocação industrial do Rio e a nova ordem estabelecida, remodelar a cidade com um zoneamento urbano bem definido e integrada a partir de um conjunto de avenidas, vias expressas, túneis e viadutos.

Essas tendências já se desenhavam, aliás, desde o fim da década de 1950, com a prefeitura de Negrão de Lima ainda nos tempos do Rio como capital federal, e foram

\footnotetext{
${ }^{5}$ O governo Juscelino Kubitschek (1955-1960) implementou o Plano de Metas, com base em estudos da CEPAL, entre outros, em que apontava a industrialização como principal meio de superar o 'atraso' do país, devendo o governo agir como incentivador e garantidos da uma infraestruturara necessária à indústria. Um dos elementos articuladores dessa política seria a opção pelo transporte rodoviário de cargas e passageiros, com a construção de estradas e a instalação de indústrias automotivas, em detrimentos de outros modais, que até hoje prevalece. Sobre o Plano de Metas ver https://cpdoc.fgv.br/producao/dossies/JK/artigos/Economia/PlanodeMetas.
} 
consolidadas no Plano Doxiadis, plano diretor para a cidade encomendado por Lacerda, permanecendo nos governos seguintes. ${ }^{6}$

E as favelas não eram 'excluídas' dessa reformulação do Rio de Janeiro. Pelo contrário, buscava se a integração do favelado nessa nova configuração urbana, tirandoo da condição de marginal e ilegal dotando-o do sentido de propriedade ao morar numa casa própria, dentro do processo de aprofundamento das relações capitalistas levado a cabo pela Ditadura, conjugando a troca do barraco na favela pelo apartamento no conjunto e a ruptura com a vida instável de 'bicos', subempregos ou mesmo o desemprego, passando para a inserção do favelado no mercado formal de trabalho como mão-de-obra minimamente qualificada e disciplinada.

Antes do fim da década de 1970, porém, a 'vocação industrial' fracassou. A instalação de indústrias, desde a década de 1930 ocorria com maior intensidade em outras regiões do país. E os removidos não se tornariam nem proprietários incorporados, nem mão de obra fabril. Os conjuntos distantes das antigas favelas e sem que um mercado local de trabalho surgisse, somado ao fato de que as causas que faziam surgir as favelas não foram combatidas, fez com que rapidamente fossem considerados novas 'favelas' (Brum, 2012: 209)

Por um lado, o programa jamais combateu de modo real as causas que faziam as favelas surgirem. Do outro, a Ditadura acirrou as desigualdades sociais no período, o que foi intensificado em seus anos finais numa espiral de crise, desemprego e inflação, além do progressivo desmonte de mecanismos de proteção social do Estado que foram

\footnotetext{
${ }^{6}$ O Plano Doxiadis, coordenado pelo escritório do arquiteto grego Konstantino Doxiadis previa a expansão da cidade do Rio de Janeiro em direção à Zona Oeste através de dois principais eixos: norte, através da avenida Brasil, onde ficariam os bairros proletários e as indústrias; e sul, com a avenida das Américas e a auto-estrada Lagoa-Barra como a via principal para bairros residenciais destinados às classes de maior poder aquisitivo Além das linhas policrômicas, vias expressas como a Vermelha e a Amarela. Nos últimos 50 anos, por diferentes governos, o plano tem se tornado realidade em grande parte. (Perez, 2007: 45)
}

RRASILIANA- Journal for Brazilian Studies. Vol. 4, n.2 (2016). ISSN 2245-4373. 
herdados do período anterior e que haviam sido consolidados na Era Vargas (Fagnani, 2005).

Desse modo, a década de 1970 chega ao fim com o número de favelas na cidade crescendo Se antes da 'Era das Remoções' a população favelada era de 335.063 em 1960, o número passou para 565.135 em 1970 e 722.424 em 1980.7 Além do fracasso do programa remocionista, a "distensão lenta, gradual e segura"8 significou a presença dos favelados na cena política com maior grau de autonomia e resistência às remoções, como os episódios do Vidigal, em 1977 e da Maré, no início da década de 1980. (Brum, 2006: 79-86)

Por outro lado, ainda, entre os motivos de abandono do programa está a abertura de uma nova frente de expansão urbana que permitiu relaxar a pressão sobre os terrenos das favelas na Zona Sul: a Barra da Tijuca, ponto que voltaremos adiante.

\section{Redemocratização e favelas: entre o controle e a permanente pedagogia do outro}

Com o fracasso do programa de remoções e a Redemocratização, as políticas de urbanização de favelas tornaram-se a tônica dos governos em todos os níveis e forças políticas a partir do final da década de 1970. E as remoções tornaram-se escassas, embora nunca tenham sumido totalmente de cena.

O retorno de um associativismo marcado pela intensa mobilização dos moradores com vistas à participação na política mais geral, tratado por nós em estudo anterior como 'de resistência', colocava no centro de sua luta uma mudança radical no Estado, desde a questão do solo urbano, à livre organização dos moradores a um governo eleito

\footnotetext{
${ }^{7}$ Dados dos Censos - IBGE para 1960 e 1970, e IplanRio para 1980 (apud. Cavallieri, 1985: 21)

${ }^{8}$ Sobre o assunto ver Gaspari, Elio A Ditadura Encurralada, São Paulo: Companhia das Letras, 2004.
}

3RASILIANA- Journal for Brazilian Studies. Vol. 4, n.2 (2016). ISSN 2245-4373. 
democraticamente e que promovesse profundas mudanças sociais, no que ganharam força nas associações de moradores de favelas lideranças mais identificadas com partidos e grupos de esquerda, como Partido dos Trabalhadores, o Partido Democrático Trabalhista, de Leonel Brizola, o Movimento Revolucionário 8 de Outubro, comunistas, entre outros... Tratava-se de mudar o país para mudar o estatuto da favela. ${ }^{9}$

Com vitórias eleitorais de forças de esquerda, para os poderes executivo e legislativo, além da própria disputa entre forças políticas que atravessou a sociedade brasileira no período, gradualmente, o Estado não apenas atendeu demandas dos moradores de favelas, levando serviços e equipamentos urbanos numa escala não vista anteriormente, mas as próprias lideranças comunitárias foram sendo incorporadas ao aparelho de estado, num processo em que clientelismo e democratização mais se confundem do que se excluem.

Se por um lado a presença de lideranças comunitários em cargos no executivo, legislativo, ou como funcionários da prefeitura e governo do Estado poderia ser lida como a abertura deste a sujeitos historicamente excluídos do poder; o processo de atendimento de demandas vinculado a essa presença foi tornando cada vez mais necessária a existência de fortes laços entre o ocupante do poder e a representação comunitária.

O incentivo à mobilização e organização comunitária das favelas cariocas pelas forças de esquerda implicava na adesão dos favelados às suas bandeiras e organizações. Nesse movimento que chamamos de pedagogia do outro. A mobilização das favelas não era o fim, mas um meio pelo qual as esquerdas alcançariam o poder.

\footnotetext{
${ }^{9}$ Sobre a trajetória histórica nas favelas nas décadas de 1980 e 1990 há uma vasta bibliografia. Em português recomendamos, além dos já citados Brum (2006) e Machado (2002), Oliveira et alli (1993), Amoroso (2015); e em inglês os livros de Perlman (2010) e McCan (2014).
} 
No entanto, do lado dos favelados, as demandas locais por serviços públicos, urbanização e equipamentos tornaram-se um reconhecimento oficial do direito à existência da favela, e fizeram com que o eixo de mobilização por mudança mais amplas na sociedade, e as formas de luta e alianças ligadas a esse eixo, fosse gradativamente sendo abandonadas. E manter o laço com o ocupante do poder, independente de qual partido fosse tornou-se vital para que a favela recebesse os serviços, obras e equipamentos.

Considerando ainda que todo esse processo de incorporação de líderes e moradores de favelas aos quadros do Estado e as ações e políticas realizadas nas favelas envolviam recursos públicos, em época de crise econômica. Ocupar um cargo numa secretaria municipal ou estadual ou prestar um serviço a ela muitas vezes significou um meio de vida.

A luta geral deu espaço ao local, ao atendimento de demandas pontuais, mais fáceis de serem alcançadas pelos laços com o governo do que longas lutas de caráter mais abstrato. E o líder comunitário mobilizador deu espaço ao líder com fácil acesso ao poder. O movimento comunitário das favelas cariocas chega à década de 1990 sem o ímpeto 'transformador' que adquiriu, em maior parte, no fim da década de 1970.

Se o 'associativismo de serviços', ou seja, a associação de moradores como um representante do Estado na favela, com prestações de serviços e recebimento de recursos, era uma permanência que vinha desde a década de 1960, e que no período da Ditadura qualquer alternativa a isso era inibida à força, consolidada a democracia no Brasil ele se tornou hegemônico.

Acesso ao poderes públicos, recursos financeiros, controle da oferta de empregos e prestação de serviços na favela... as associações de moradores se tornaram alvo da cobiça de outros poderes que foram se instaurando nas favelas na década de 1980 e 1990 
como o tráfico de drogas, que a partir da década de 1980 passam a disputar o controle das associações, com severas conseqüência a quem se opusesse a isso. ${ }^{10}$

A consolidação da favela no plano político, tanto quanto quaisquer outros territórios da cidade que ainda partilham de um status inferior, ocorreu nas décadas de 1980 e 1990, como apontou Luiz Antonio Machado da Silva:

A 'vitória da favela' ocorreu à custa da constituição de uma categoria social subalterna, cuja intervenção na cena pública, duramente conquistada, não mexeu no padrão de sociabilidade urbana, pouco alterando sua posição relativa na estratificação social e seu papel como força social. (Machado da Silva, 2002: 223-4)

Vale dizer ainda que, enquanto os favelados se afirmavam na cena política, processos paralelos trouxeram sérios obstáculos a uma cidadania plena, como a atuação de quadrilhas ligadas ao tráfico de drogas, em que direitos humanos passaram a ser identificados como direitos de bandidos (Caldeira, 2000). O que, por exemplo, impediu a construção de consensos sobre uma política de segurança pós-Ditadura que respeitassem o domicílio e a dignidade dos moradores de favela.

Assim, se por um lado o voto e a mobilização política dos moradores de favela foram forças consideráveis no quadro político, por outro, as décadas de crise e estagnação econômica e o crescimento da violência derivada da atuação do tráfico de drogas fez com que as favelas passassem a figurar como áreas em que a atuação de quadrilhas de traficantes fazia com que a violência urbana transbordasse para a cidade.

\footnotetext{
${ }^{10}$ Como podemos ver em reportagem de 1987: "Nos últimos meses tomou corpo na base do movimento uma série de acontecimentos cuja característica principal é o confronto das lideranças comunitárias com representantes do crime organizado" "(Falange toma associações para controlar o tráfico" Jornal do Brasil, 19/11/1987)
} 
E seus moradores, em situação de pobreza, seriam coniventes com o tráfico por necessidade.

De modo que o tráfico foi um obstáculo para realização de uma cidadania plena por parte dos moradores de favelas cariocas, tanto pelas restrições à autonomia de suas organizações quanto por uma espécie de justificativa para uma ação dura da polícia nas favelas e discursos que defendiam a volta das remoções como solução possível. ${ }^{11}$

Ao chegar o ano 2000, o número da população favelada na cidade do Rio de Janeiro alcançou 1.092.476 moradores ${ }^{12}$. Sem embargo, no quadro atual, remover Rocinha, o Alemão ou a Maré, complexos de favelas que podem ter, dependendo da fonte, até 200 mil moradores, tornou-se uma tarefa cujos custos políticos e econômicos seriam altíssimos. De modo que o tráfico, num certo sentido, é também um fator que impôs as favelas na agenda pública de qualquer governo, demandando soluções que tornem sua presença na paisagem carioca menos conflituosa.

Desse modo, as favelas também passaram a ser objeto de políticas que 'resgatassem a cidadania' de seus moradores. No que a infinidade de ações e projetos sociais realizados pelo Estado, organizações não governamentais e empresas são exemplo do fenômeno que associa pobreza e criminalidade (Zaluar, 2004). O que de certo modo é uma reatualizaçãodo estigma do favelado, principalmente sobre a juventude, que se não for 'resgatada' por um projeto ou ação social, caminhará inexoravelmente para criminalidade. A pedagogia do outro em ação...

\footnotetext{
${ }^{11}$ Para ilustrar o primeiro caso temos a frase do atual secretário estadual de Segurança Pública, José Beltrame, "Um tiro em Copacabana é uma coisa. Na Favela da Coréia é outra". ("Beltrame: 'Um tiro em Copacabana é uma coisa. Na Favela da Coréia é outra'. OAB critica diferenciamento" $O$ Globo, 23/10/2007). No caso da defesa à remoção, temos o editorial do editorial do Jornal do Brasil (de 17/04/2004), com o título "Favelas: Agenda Maldita", em que afirma categoricamente, como uma das medidas a serem tomadas para resolver a questão da segurança: "Não há mais como fugir de um programa sério de longo prazo que passe pela remoção da favela.”

${ }^{12}$ Instituto Brasileiro de Geografia e Estatística - IBGE / Base de informações por setores do Censo Demográfico 2000 - Tabulação IPP/DIG
} 
No entanto, parte do movimento comunitário das favelas cariocas, junto com outros atores como a academia, conseguiu construir uma percepção de que a resolução da violência passa necessariamente pela construção de uma pauta positiva de direitos a serem garantidos pelo Estado. $\mathrm{O}$ que foi consagrado, ao menos no discurso, na atual política de implementação das UPPs, como aponta Burgos et alli (2012: 94-5), ao tratar da série de reportagens “Democracia nas Favelas", publicadas do jornal O Globo em 2009:

É notável, ainda, a mudança de enquadramento desta série - em que a cidadania dos moradores de favelas é valorizada como ângulo privilegiado para se analisar a UPP, em contraposição às imagens já consagradas das favelas como redutos do crime e de criminosos, reais ou potenciais.

Após o Caso Amarildo, pedreiro desaparecido na Rocinha em junho de 2013 por policias da UPP local, as UPPs passam a viver uma profunda crise, em que a 'nova polícia', como anunciado pelo Governo do Estado foi dando esapço às velhas práticas policiais já conhecidas, principalmente, pelos moradores de favelas: corrupção, extorsão, desrespeito aos direitos dos moradores e violência, frequentemente, letal.

No entanto, as UPPs tinham grande aceitação por parte dos moradores. ${ }^{13}$ Ainda que pelo viés oposto ao que o Estado declarava: as UPPs, mais do que se tratarem de

\footnotetext{
${ }^{13}$ Um panorama da trajetória das UPPs pode ser feito a partir dos seguintes estudos: Machado da Silva, Luiz Antonio, 2010 "Afinal, qual é a das UPPs" Disponível em www.observatoriodasmetropoles.ufrj.br (Acessado em 06/25/2015; Cunha, Neiva Vieira da e Mello, Marco Antonio da Silva. Novos conflitos na cidade: A UPP e o processo de urbanização na favela. Dilemas: Revista de estudos de conflito e controle social, Rio de Janeiro, v. 4, n. 3, p. 371-401, jul.-set. 2011. Cano, Ignacio; Borges, Doriam ; Ribeiro, Eduardo 2012 Os Donos do Morro: Uma análise exploratória do impacto das Unidades de Polícia Pacificadora no Rio de Janeiro. 1. ed. São Paulo: Forum Brasileiro de Segurança Pública; Amoroso, Mauro; Brum, Mario et Gonçalces, Rafael Soares , « Police, participation et accès aux droits dans desfavelas de Rio de Janeiro: l'expérience des Unités de police de pacification (UPP) », L'Ordinaire des Amériques [En ligne], 216 | 2014: http://orda.revues.org/1014
} 
uma política de pacificação de favelas, significava, na leitura dos moradores de favelas, um projeto de pacificação da polícia (como tratamos em co-autoria em artigo anterior Burgos et alli, 2012: 91).

A incorporação da 'cidadania' dos moradores de favelas também se dá por outro viés, em voga em tempos de aprofundamento das relações de mercado e neodesenvolvimentismo: ${ }^{14}$ a incorporação das favelas à ordem urbana através do consumo e da formalização, dentro do novo projeto de reformulação urbana do Rio como Cidade Global, novas funções e novos lugares da pobreza urbana.

\section{As favelas e o novo ciclo do Rio: a cidade ambiente de negócios}

Perda da condição de capital, fracasso da vocação industrial, perda do status de estado (com a fusão da Guanabara com o Estado do Rio de Janeiro, em 1975, com a declaração do novo governador, Almirante Faria Lima, de que o tratamento dado ao Rio seria de apenas 'um município como outro qualquer' Motta, 2001:29).

O Rio entrou na década de 1980 sob impactos de opções econômicas e políticas que levaram o Estado, e a cidade a uma crise maior que vivida pelo país nas décadas de 1980 e 1990. Para Osório (2013: 191-2):

pode-se afirmar que os territórios carioca e fluminense, por derivarem o seu dinamismo econômico centralmente da história de capitalidade da cidade do Rio de Janeiro, sofreram, a partir dos anos 1960, um processo

\footnotetext{
${ }^{14}$ Sobre a discussão do conceito de neodesenvolvimentismo, recomendamos a leitura do debate entre Andre Singer e Armando Boito Jr. em http://jornalggn.com.br/blog/antonio-ateu/debate-politica-e-estrutura-de-classe-no-brasil-pos1988.
}

RRASILIANA- Journal for Brazilian Studies. Vol. 4, n.2 (2016). ISSN 2245-4373. 
de erosão da sua importância e do seu dinamismo econômico-social. O entendimento dessa questão, no entanto, não é realizado de forma imediata, pelos próprios cariocas e fluminenses, só ocorrendo nos anos 1980, com a inversão do processo de crescimento da economia brasileira e a crise fiscal que então se instaura, atingindo particularmente o Estado do Rio de Janeiro, pelo peso que o gasto federal ainda tinha na região.

A partir do final da primeira década do século XXI, fruto da retomada do crescimento do país, a ascensão econômica de um largo contingente da população mais pobre nos anos 2000 e o impulso que a Indústria de Petróleo e Gás no Estado do Rio de Janeiro tomou, com a descoberta de importantes jazidas, criaram uma atmosfera de 'retomada' da cidade e do Estado, de superação das décadas de crise simbolizadas pelo número de eventos internacionais em que a cidade é sede em curto espaço de tempo: Conferência Rio+20; V Jogos Mundiais Militares, II Jornada Mundial da Juventude da Igreja Católica; Copa do Mundo de Futebol da FIFA (uma das cidades sedes); Jogos Olímpicos de 2016.

Além dos mega-eventos que sediará, a região metropolitana do Rio de Janeiro tem se tornado destacado pólo de atração de investimentos nacionais e internacionais ${ }^{15}$. Essa 'Década de Ouro', conforme a prefeitura batizou oficialmente a comemoração do Reveillon de $2011^{16}$, tem como um dos seus principais pressupostos o empenho na configuração de todo território urbano, favelas inclusive, como um seguro ambiente de negócios.

\footnotetext{
${ }^{15}$ Segundo dados da FIRJAN (Federação das Indústrias do Estado do Rio de Janeiro), o estado do Rio entre $2011 \mathrm{e}$ 2013 teve a maior concentração de investimentos públicos e privados do mundo. Ver em: http://www.firjan.org.br/data/pages/2C908CEC32686D3D013281E03F48787B.htm Consultado em 12/11/2013.

16 Ver http://www.jb.com.br/rio/noticias/2010/12/31/reveillon-2011-abre-a-decada-de-ouro-do-rio-de-janeiro. Consultado em 06/25/2015.
}

RRASILIANA- Journal for Brazilian Studies. Vol. 4, n.2 (2016). ISSN 2245-4373. 
Tratamos da atual política de remoções, e toda lógica que a move em outro artigo (Brum, 2013), de modo que aqui nos ateremos ao que consideramos ser o principal escopo da gestão da pobreza num Rio Global, de modo que grandes agentes de mercados tenham pleno acesso, passando pela formalização de um mercado de consumo crescente como o das favelas, que movimenta 12 bilhões por ano ${ }^{17}$. Prova desse vigoroso mercado é que desde antes de 2008 bancos e grandes franquias já estavam instalados em favelas.

É um projeto bem articulado, com poderosas organizações da sociedade civil ligadas ao empresariado ou pensadores de corte neoliberal, em que suas raízes remontam a período anterior a escolha do Rio como sede das Olimpíadas de 2016, feita em outubro de 2009 e a implantação das UPPs (ocorrida a partir de dezembro de 2008).

É possível reconstituir os passos dessas formulações através de seus protagonistas:

Em 2006, a Federação do Comércio do Estado do Rio de Janeiro (Fecomércio) elaborou uma proposta de desenvolvimento de longo prazo para o Estado do Rio de Janeiro, em que dois dos sete eixos prioritários eram:

- Território do incentivo e das sinergias para o empreendorismo, visando tornar o Rio de Janeiro um território fácil e amigável para abrir, regularizar e manter seu negócio

- Desenvolvimento do mercado-base da pirâmide, que passa pelo amplo reconhecimento dos direitos de propriedade e visa

\footnotetext{
17 Ver http://www.ebc.com.br/noticias/brasil/2014/09/moradores-de-favelas-do-rio-movimentam-r-123-bilhoes-porano. Consultado em 06/25/2015.
} 
transformar o Rio de Janeiro no território líder em estratégias empresariais voltadas a esse segmento do mercado ${ }^{18}$

Esses empresários e pensadores se unem em abril de 2007, no seminário “A reinvenção do futuro das grandes metrópoles e a nova agenda de desenvolvimento econômico e social da América Latina", organizado pela Associação Comercial do Rio de Janeiro (ACRJ), pelo Instituto de Estudos do Trabalho e Sociedade (IETS) e Instituto Fernando Henrique Cardoso. Na convocação do seminário encontramos uma descrição do quadro das economias latinoamericanas e o papel que as cidades podem desempenhar:

não tendo sido capazes de completar o ciclo de reformas institucionais iniciado na década passada, não conseguem capturar plenamente as oportunidades propiciadas pela extraordinária expansão da economia mundial nos últimos anos." E de que "a agenda reformista está incompleta. Falta-lhe um componente importante, que é o da reinvenção do futuro das grandes metrópoles. ${ }^{19}$

Temos nesse seminário alguns componentes importantes na formulação e execução da implantação de um ambiente de negócios no Rio. O economista Andre Urani, falecido em 2011, destacou-se como um dos mais completos analistas e formuladores de políticas nesse sentido. Foi ele um dos elaboradores do plano de desenvolvimento para o estado

\footnotetext{
${ }^{18}$ Ainda em 2008, André Urani publicou o livro "Trilhas para o Rio: do reconhecimento da queda à reinvenção do futuro", onde diversas formulações que posteriormente se tornaram políticas efetivas, ou valiosas análises que guiam essas políticas estão ali escritas.

${ }^{19} \mathrm{http}: / / \mathrm{www}$.iets.org.br/a-reinvencao-do-futuro-das-grandes-metropoles-e-a-nova-agenda-dedesenvolvimentoeconomico-e-social-da-america-latina consultado em 06/20/2015
}

RRASILIANA- Journal for Brazilian Studies. Vol. 4, n.2 (2016). ISSN 2245-4373. 
feito em 2006 pela Fecomércio. Já a ACRJ é uma das organizações responsáveis pelo funcionamento regional do Serviço Brasileiro de Apoio às Micro e Pequena Empresa (SEBRAE), que tem se tornado um dos principais implementadores da política de formalização e empreendedorismo nas favelas cariocas.

Ainda em 2008, no mês de agosto, os temas da informalidade e ilegalidade nas favelas foram tratados na série de reportagens "Favela S.A." do Jornal O Globo, principal jornal da cidade e ligado ao mais poderoso grupo de mídia no Brasil. $\mathrm{Na}$ abertura da série encontramos o descrição da situação:

Os moradores formam uma massa de potenciais consumidores estimada entre 1,3 milhão e dois milhões de pessoas, com renda anual que pode chegar a algo entre $\mathrm{R} \$ 5$ bilhões e $\mathrm{R} \$ 10$ bilhões. Números que, a despeito de divergências estatísticas, fazem tinir cifrões nos olhos de qualquer empresário. Seja no varejo ou no atacado, no oficial ou no paralelo, a holding Favela S/A enriquece poucos, explora milhares e dá calote no Estado. ${ }^{20}$

Quase um ano mais tarde, em abril de 2009, começa a série de encontros OsteRio, num restaurante da Zona Sul carioca promovidos pela ACRJ, com apoio do IETS e da Light. Esses encontros reuniam autoridades, acadêmicos, jornalistas, empresários e visavam "promover um debate aberto e sistemático sobre o futuro do Rio de Janeiro", produzindo sistematizações publicadas no sítio eletrônico do IETS que no fornecem preciosas pistas dessas formulações e articulações.

20 “Sem direitos econômicos, favelas movimentam bilhões". O Globo, 08/24/08 
Dentre as várias sessões do OsteRio, temos temas como 07/12/2009: "O direito à propriedade na experiência transformadora do Cantagalo", que contou com Paulo Rabello de Castro na mesa, um dos fundadores do Instituto Atlântico, organização que executou o projeto de regularização fundiária na favela do Cantagalo, localizada num dos endereços mais nobres do Rio de Janeiro, no bairro de Ipanema, como descrito em sua página eletrônica:

No Projeto Cantagalo, o Instituto promoveu a primeira ação de usucapião coletiva contra uma Fazenda Pública do Rio de Janeiro (a Constituição do Estado do Rio de Janeiro foi alterada e abriu caminho para a transferência da propriedade plena pelo Estado), conseguiu o reconhecimento de posse de $54 \%$ das moradias da favela do Cantagalo e escritura definitiva até agora para 3\% dos moradores. ${ }^{21}$

O Instituto Atlântico é uma think tank fundada em 1993. E como vemos em outro projeto encabeçado pelo instituto, o Movimento Brasil Eficiente, defende uma agenda de reformas identificada com o ideário neoliberal: redução da carga tributária, redução do papel do estado, reforma previdenciária. No que conta com apoio de grandes empresas nacionais e multinacionais, como a Walmart, dentre outras.

O Projeto Cantagalo contou com a participação da associação de moradores local, o apoio de dois escritórios de advocacia e o financiamento do Instituto Gerdau, fundação ligada a um dos maiores grupos empresariais do país, cujo presidente, Jorge Gerdau

\footnotetext{
${ }^{21} \mathrm{http}$ //www.atlantico.org.br/pt/institucional/quem-somos Consultado em 07/05/2015 Mais sobre o projeto pode ser encontrado no livro "Galo cantou: a conquista da propriedade pelos moradores do Cantagalo" de autoria de Paulo Rabello de Castro
} 
Johanpeter também se encontra à frente do Movimento Brasil Competitivo, de ideias similares ao Brasil Eficiente.

Na página do IETS que trata sobre esse encontro temos o que significaria, enfim, a regularização fundiária: "Na prática isso significa poder fazer benfeitorias, alugar, vender ou usar o imóvel como garantia num negócio, como faz qualquer proprietário 'do asfalto'." 22 Mais do que se tratar de uma adesão às ideias do peruano Hernan de Soto apresentadas no livro em O Mistério do Capital.

O Cantagalo é um dentre os vários casos (Rocinha, Alemão, Vidigal...) de regularização fundiária que vêm sendo empreendidos pelo próprio Estado, embora isso seja dificultado por várias questões burocráticas da legislação brasileira e municipal sobre a ocupação do solo urbano. ${ }^{23}$

Embora deva ser considerado que a luta pela propriedade da terra tenha sido historicamente uma bandeira do movimento comunitário, tratamos anteriormente (Brum, 2006) que houve um descolamento em seu eixo de mobilização. Se na conjuntura até o fim dos anos 1970 a remoção era uma ameaça permanente e as favelas não eram oficialmente reconhecidas como parte da cidade, o que demandava uma luta por mudanças na lei e mesmo na forma de governo (traduzidas na luta pelo "fim da Ditadura"), a partir da década de 1980 as políticas de urbanização por parte dos três níveis de governo e por todas as forças políticas deslocaram as reivindicações por políticas pontuais de urbanização, que ao mesmo tempo era um reconhecimento oficial do Estado da existência da favela. A luta pela posse da terra foi extremamente secundária ou até mesmo inexistente nos 30 anos seguintes.

\footnotetext{
${ }^{22} \mathrm{http} / / /$ www.iets.inf.br/article.php3?id_article=1495 Consultado em 06/29/2015

23 “Cerca de 103 mil imóveis em favelas, ou 23\% do total, estão em processo de regularização" $O$ Globo, $12 / 29 / 2013$.
}

3RASILIANA- Journal for Brazilian Studies. Vol. 4, n.2 (2016). ISSN 2245-4373.

(C) $\mathbb{Q} \Theta \Theta$ 
Sem embargo, se antes a propriedade da terra seria a garantia definitiva contra a remoção, para parte do movimento comunitário, hoje ela pode se tornar exatamente o instrumento para um processo mais lento e suave de expulsão dos moradores. Muito mais radical e efetivo, no entanto. Ao morador proprietário caberá as regras do mercado e os custos cada vez mais altos de uma favela dentro da formalidade e incorporada à ordem.

Custos pelo pagamento de serviços que antes eram burlados pelos moradores por diversas estratégias. $\mathrm{O}$ atual projeto de cidade que se quer construir passa pela 'reeducação' dos moradores de favelas, e esse é o principal sentido das UPPs, e sua incorporação.

A Light, companhia privada de eletricidade, por exemplo, têm tido forte atuação nas favelas com UPP, combatendo a tradicional lógica dos 'gatos' de luz, como podemos ver em dois relatórios da companhia aos acionistas:

A parceria com o Governo do Estado do Rio de Janeiro, que, por meio das Unidades de Polícia Pacificadora (UPPs), possibilitou a entrada da Light em locais onde antes não era possível prestar um bom serviço. Respeitados e regularizados, os moradores das comunidades cariocas passaram a pagar pela energia consumida, impactando o capital financeiro na medida em que a regularização do consumo elevou a arrecadação da light. ${ }^{24}$ (Light, 2014: 56)

Das 34 comunidades que já contam com Unidades de Polícia Pacificadora (UPP), a Light está presente em 17 delas e já concluiu a

\footnotetext{
${ }^{24}$ Light: Relatório de Sustentabilidade 2014 - Light (p. 56)
} 
reforma da rede em nove, registrando uma redução média das perdas de 53,0 p.p. (de $64,1 \%$ para $11,1 \%$ ) e aumento médio da adimplência de 88,9 p.p. $(\text { de } 9,6 \% \text { para } 98,5 \%)^{25}$

Outro ponto central da política articulada pelo Estado e iniciativa privada tem se dado através da formalização dos serviços e comércio das favelas.

Se antes da década de 1980 as favelas eram caracterizadas, oficialmente, como áreas predominantemente residenciais, o panorama sofreu significativas alterações nas últimas décadas. A verticalização das favelas em paralelo à crise econômica nas décadas de 1980 e 1990 levou a uma explosão de pequenos negócios nas favelas ${ }^{26}$ majoritariamente informais.

Em 2011, logo após o processo de implantação da UPP na Rocinha, um editorial do Globo faz a defesa da formalização como necessidade premente para uma mudança profunda na cidade:

Nesse processo de melhora espera-se que Rocinha, Vidigal e Chácara do Céu se integrem mais à cidade formal, reduzindo a distância entre o morro e o asfalto, como se dizia antigamente (hoje já não há por que existirem ruas sem pavimentação nas comunidades). Trata-se de uma mudança cultural importante, pois, junto com o avanço da

\footnotetext{
${ }^{25}$ Light: Relatório da Administração ano 2013 - Light S.A.- 2013 (p. 28)

${ }^{26}$ Pesquisas têm apontado que o empreendorismo no Brasil ocorre mais por necessidade do que por oportunidade. Geralmente é a perda do emprego e a dificuldade de realocação no mercado de trabalho que leva à iniciativa. (“Empreendedorismo no Brasil acontece por necessidade, revela estudo" Folha de São Paulo, 11/14/2002)
} 
criminalidade, a informalidade se tornou o padrão das atividades econômicas dentro de tais comunidades. ${ }^{27}$

Vale dizer que, em 2009, na sintonia dos encontros da OsteRio e das formulações da ACRJ, do IETS, entre outros, o jornal publicou uma outra série de reportagens com o mote "Ilegal, e daí?" com amplas narrativas sobre a desordem urbana na cidade, inclusive nas favelas.

Desse modo, na esteira da implantação das UPPs a ACRJ e o Sebrae-RJ têm realizado o Programa de Empreendedorismo em Áreas Pacificadas, em favela com UPPS, que junto com o poder público atua no incentivo ao empreendedorismo e também na formalização dos pontos de comércio das favelas.

O governo do estado atua na formalização e no apoio ao empreendedorismo através do AgeRio, agência estadual de fomento que estimula o microcrédito aos moradores de favela, e mais recentemente, a prefeitura do Rio, além de leis e decretos que objetivam a implementação do processo, através do programa Rio + Social, originalmente batizado de UPP Social, mas que acabou tendo como o principal eixo de atuação o "desenvolvimento econômico - com formação, consultoria e auxílio em legalização para empreendedores locais visando à geração de renda e emprego nas comunidades $^{\prime 28}$

O processo de formalização foi facilitado pelo Governo Federal pela Lei Complementar 128, de 2008, que cria a figura jurídica do microempreendedor, microempresários cujo negócio movimente até 60 mil reais por ano (aproximadamente 19 mil dólares).

\footnotetext{
27 “Formalizar a Rocinha é a nova missão" (O Globo, 11/20/2011)

${ }^{28}$ http://www.riomaissocial.org/programa/ Consultado em 06/29/2015
}

RRASILIANA- Journal for Brazilian Studies. Vol. 4, n.2 (2016). ISSN 2245-4373. 
Além de garantias previdenciárias ao microempresário, a medida permite emissão de nota fiscal. No caso das favelas cariocas, esse ponto é consideravelmente importante, pois permite a realização de negócios do microempresário local com agentes externos à favela. Liga-se, por vias legais, a favela à cadeia de produção. Além disso, trata-se do principal meio de controle para arrecadação fiscal por parte do poder público. Caminha-se a passos firmes para um ambiente seguro de negócios.

Assim, diversas iniciativas do SEBRAE com apoio do Estado e empresas privadas têm estimulado o encontro de grandes empresas com o comerciante e prestador de serviços locais nas favelas. Desde feiras gastronômicas a eventos para obtenção de crédito.

Tal processo é defendido pelas autoridades como uma garantia contra o o risco que a valorização dos imóveis nas favelas acabe por expulsar os moradores, sendo a solução o incentivo ao empreendorismo:

Em função desse risco, o governo do Estado, a Prefeitura do Rio e entidades de apoio ao empreendedorismo, como o Serviço Brasileiro de Apoio à Micro e Pequena Empresa (Sebrae-RJ), vêm desenvolvendo projetos e ações de estímulo ao desenvolvimento sustentável dos negócios nas favelas pacificadas, como forma de permitir que seus moradores se integrem ao processo de mudanças que precisam acompanhar os investimentos. ${ }^{29}$

29 "Nas comunidades pacificadas, o mercado integra" (Revista Economia Rio, ano 1, n. 4 dezembro 2014 pp. 37-41) 


\section{Conclusão}

A regularização fundiária, a formalização dos pequenos negócios a favela, as UPPs... são elementos fundamentais para o novo lugar da pobreza urbana no Rio de Janeiro hoje.

Nesse sentido, afirmamos que as Unidades de Polícia Pacificadora (UPPs) e as remoções, embora sejam os elementos mais visíveis e dramáticos a curto prazo, não são as principais políticas direcionadas às favelas do Rio de Janeiro. Assim, há uma forte percepção por parte dos moradores das áreas 'pacificadas' de que as UPPs atuam menos como promotoras de direitos e mais como garantidos de deveres através da manutenção da permanente face repressora da polícia, onde o que 'não se pode fazer' tem prevalecido em relação à promoção dos direitos. Outras empresas, como telefonia e TV a Cabo, também têm atuado com força em áreas de UPP, cujos pontos de venda chegam literalmente, junto com as ocupações policiais que antecedem às UPPs.

Não se trata aqui de defender a permanência da ilegalidade ou um adotarmos um tom paternalista que deixe as favelas sob históricas características de segregação urbana, no que a leitura da favela como território do "Ilegal e daí?" não deve ser tratada como insuperável.

Vejamos como a prefeitura apresenta o atual processo de regularização fundiária. Para prefeitura, a regularização fundiária tem

o objetivo de reconhecer e garantir a segurança da posse e o acesso ao título de propriedade pelo morador. A iniciativa visa contribuir para ampliar os direitos de cidadania da população das regiões beneficiadas, através da moradia digna, da qualificação do ambiente urbano e da existência jurídica e administrativa da habitação. Além disso, busca-se 
ainda a inserção das áreas regularizadas nas rotinas de planejamento e controle do uso e ocupação do solo da cidade, complementando as melhorias que acompanham as obras de urbanização. ${ }^{30}$ [grifo nosso]

Essa rotina de controle é uma permanência da relação da cidade com as favelas. Combatese a informalidade e a ilegalidade que marcam a trajetória histórica da favela com a sua incorporação ao conjunto da cidade.

Assim, a criação de um ambiente de negócios seguro no Rio de Janeiro passa pela incorporação dos territórios historicamente segregados a uma ordem que já possui os vencedores estabelecidos, que passam a ter pleno acesso e controle a territórios urbanos anteriormente segregados, num contexto de maior penetração do capital, e de inclusão no consumo, em que essa expansão do mercado configure-o como horizonte (não apenas possível, mas ideal) para inclusão das favelas à Cidade Global.

\section{Bibliografia}

Amoroso, Mauro. Caminhos do lembrar: a construção e os usos políticos da memória no morro do Borel. Rio de Janeiro: Ponteio, 2015.

Benmerguí, Leandro. “The Alliance for Progress and housing policy in Rio de Janeiro and Buenos Aires in the 1960s" Urban History. n. 36, jul/2009. p. 303-326

Brum, Mario. "O povo acredita na gente": Rupturas e continuidades no movimento comunitário das favelas cariocas nas décadas de 1980 e 1990. Dissertação de Mestrado em História Social. Niterói: PPGH/UFF, 2006.

\footnotetext{
${ }^{30} \mathrm{http}: / / w w w . r i o . r j . g o v . b r / w e b / s m h / e x i b e c o n t e u d o ? i d=155822$ Consultado em 06/20/2015
} 
. Cidade Alta. Rio de Janeiro: Ponteio, 2012

- "Favelas e remocionismo ontem e hoje: Da Ditadura de 1964 aos Grandes Eventos", Revista O Social em Questão, n.29. v.1 PUC-Rio/Depto de Serviço Social.

Burgos, Marcelo; Cavalcanti, Mariana; Brum, Mario; Amoroso, Mauro; Pereira, Luiz Fernando Almeida. "O efeito UPP na percepção dos moradores das favelas". Desigualdade E Diversidade (PUCRJ), v. 11, 2012, pp. 49-97.

Cavallieri, Paulo Fernando. Favelas Cariocas: Mudanças na infra-estrutura. In Ferreira (org.). Quatro Estudos. Rio de Janeiro: IPLANRIO, 1985 pp 20-4

Fagnani, Eduardo. Política Social no Brasil (1964-2002): Entre a Cidadania e a Caridade. Tese de Doutorado em Economia. Campinas: IE-Unicamp, 2005

Gonçalves, Rafael. Favelas do Rio de Janeiro: História e Direito. Rio de Janeiro: Pallas/PUCRio, 2013

GOVERNO DA GUANABARA. Aspectos da geografia das indústrias no Rio de Janeiro. Rio de Janeiro, 1969

Motta, Marly Silva da. "A fusão da Guanabara com o Estado do Rio: desafios e desencantos". In: Um Estado em questão: os 25 anos do Rio de Janeiro. FREIRE, Américo; Sarmento, Carlos Eduardo; Motta, Marly Silva. Rio de Janeiro: Ed. Fundação Getulio Vargas, 2001. Pp.19-56.

McCan, Bryan. Hard Times in the Marvelous City: From Dictatorship to Democracy in the Favelas of Rio de Janeiro. Durham, N.C.: Duke University Press, 2014. 
Osorio, Mauro; Versiani, Maria Helena. "O papel das instituições na trajetória econômico-social do Estado do Rio de Janeiro". Cadernos do Desenvolvimento Fluminense, Rio de Janeiro, n.2, julho/ 2013 pp. 188-210

Perez, Maurício. Lacerda na Guanabara - A Reconstrução do Rio de Janeiro. Rio de Janeiro: Odisséia Editorial, 2007.

Perlman, Janice. Favela. Four decades of living on the edge in Rio de Janeiro Nova York: Oxford University Press, 2010

Oliveira, Anazir Maria de et alli. Favelas e organizações comunitárias. Petrópolis: Vozes, 1993;

Vaz, Lilian Fessler. Contribuição ao Estudo da Produção e Transformação do Espaço da Habitação Popular. As Habitações Coletivas do Rio Antigo. Dissertação de Mestrado em Planejamento Urbano. Rio de Janeiro: PUR/UFRJ, 1985.

Zaluar, Alba. Integração perversa: pobreza e tráfico de drogas. Rio de Janeiro: FGV, 2004. 